\title{
Rousseau: do estado natural ao estado civil
}

\author{
Submetido em: 10/08/2020, aprovado em: 08/12/2020 \\ 10.30612/mvt.v7i13.12586 \\ Michel Goulart da Silva'
}

\begin{abstract}
Resumo: Neste ensaio, articulando as obras $O$ contrato social (1762) e Discurso sobre a origem e os fundamentos da desigualdade entre os homens (1755), são discutidos o estado de natureza e a passagem para o estado civil, conforme apresentados pelo autor. No primeiro livro apresenta-se uma forma de analisar a configuração da sociedade em seu estado civil, com o funcionamento das leis e de governos, enquanto no segundo trata-se do período anterior à institucionalização das relaçôes entre os homens, discutindo uma possível caracterização do surgimento da desigualdade e apontando, entre outros aspectos, a origem da propriedade.
\end{abstract}

Palavras-chave: Rousseau, Classe sociais, Desigualdade.

\section{Rousseau: from the natural state to the civil status}

Abstract: This essay, articulating the work The Social Contract (1762) and Discourse on Inequality (1755), are discussed in the state of nature and the passage to the marital status, as presented by the author. In the first book presents a way to analyze the configuration of society in their marital status, with the operation of laws and governments, while in the second it is the period prior to the institutionalization of relations between men, discussing a possible characterization of the emergence of inequality and pointing, among other things, the origin of property.

Keywords: Rousseau, Social Class, Inequality.

\section{Rousseau: del estado natural al civil}

Resumen: En este ensayo, articulando las obras El contrato social (1762) y Discurso sobre los orígenes de los fundamentos de la desigualdad entre los hombres (1755), se discute el estado de naturaleza y la transición al estado civil, tal como lo presenta el autor. No primero es una forma de analizar la configuración de la sociedad en su estado civil, como el funcionamiento de las leyes y los gobiernos, en la segunda etapa se aborda el período anterior a la institucionalización de las

1 Doutor em História pela Universidade Federal de Santa Catarina (UFSC). Realizou estágio pós-doutoral no Programa de Pós-Graduação em História da Universidade do Estado de Santa Catarina (UDESC). Atua no Instituto Federal de Educação, Ciência e Tecnologia Catarinense (IFC). 
relaciones entre los hombres, discutiendo una posible caracterización del surgimiento de la desigualdad y apuesta, entre otros aspectos, en el origen de la propiedad.

Palabras clave: Rousseau, clase social, desigualdad.

\section{INTRODUÇÃO}

Em algumas de suas obras, Jean-Jacques Rousseau buscou relacionar a origem da desigualdade social com o processo que levou do estado natural ao contrato social estabelecido entre os homens. Segundo Rousseau (1979, p. 144), "todas as filosofias que examinaram os fundamentos da sociedade sentiram a necessidade de remontar até o estado natural, mas nenhuma conseguiu”. Essa afirmação de Rousseau parece estar relacionada com a tentativa de analisar as possíveis origens das desigualdades econômicas e sociais, em um cenário de profundas transformaçôes na Europa. O período, marcado pelas chamadas revoluçóes burguesas, possibilitou a Rousseau não apenas formular uma interpretação acerca da desigualdade como também apontar para os caminhos que poderiam ser trilhados no sentido de superação das contradiçôes sociais existentes nas sociedades do Antigo Regime.

Neste ensaio, articulando algumas das ideias desenvolvidas em obras como $O$ contrato social (1762) e Discurso sobre a origem e os fundamentos da desigualdade entre os homens (1755), serão discutidos o estado de natureza e a passagem para o estado civil. No Contrato Rousseau analisa a configuração da sociedade em seu estado civil, com o funcionamento das leis e de governos. No Discurso Rousseau discute o período anterior à institucionalização das relaçóes entre os homens, discutindo uma possível caracterização do surgimento da desigualdade e apontando, entre outros aspectos, a origem da propriedade.

\section{DO ESTADO NATURAL AO ESTADO CIVIL}

Somente no século XIX, quando a burguesia encontrava-se no poder do Estado e as desigualdades não apenas estavam longe de serem resolvidas como se aprofundavam, foi elaborada uma formulaçáo teórica que apontava para a possibilidade de superação do sistema econômico, o marxismo. ${ }^{2}$ Uma das possíveis razôes para a limitação teórica da análise de Rousseau acerca da questão da desigualdade passa, de um lado, pelo fato de ser ele um intelectual que representa os interesses da classe social em ascensão no Antigo Regime e, por outro, devido ao incipiente desenvolvimento da organização do proletariado, onde a luta de classes ainda não o colocava claramente em campos opostos com a burguesia. Para Marx e Engels (2005, p. 47),

nessa fase, o proletariado constitui massa disseminada por todo o país e dispersa pela concorrência. A coesão maciça dos operários não é ainda o resultado de sua própria união, mas da união da burguesia que, para atingir seus próprios fins

\footnotetext{
2 Segundo Coutinho (2011, p. 25), "lendo esse texto [Discurso], podemos constatar que a articulação dialética entre propriedade privada, divisão do trabalho e alienação não foi feita pela primeira vez em $A$ ideologia alemã, escrita entre 1845 e 1846. Quase cem anos antes, embora de modo menos sistemático, essa articulação já era utilizada por Rousseau como o principal instrumento conceitual da análise crítica da sociedade burguesa de seu tempo. Também não é difícil perceber, no Discurso, a antecipação de outros conceitos decisivos do materialismo histórico como, por exemplo, o vínculo orgânico entre o desenvolvimento das forças produtivas e a gestaçáo de diferentes modos de produçáo e formaçóes sociais”.
} 
políticos, é levada a pôr em movimento todo o proletariado, o que por enquanto ainda pode fazer. Durante essa fase, os proletários não combatem seus próprios inimigos, mas os inimigos dos seus inimigos, os restos da monarquia absoluta, os proprietários de terra, os burgueses não-industriais, os pequenos burgueses. Todo o movimento histórico está desse modo concentrado nas mãos da burguesia e qualquer vitória alcançada nessas condições é uma vitória da burguesia.

Na obra de Rousseau o conceito de classes sociais aparece pouco definido, sendo com frequência utilizado o termo povo, remetendo-se a um sujeito histórico genérico que, em uma descrição bastante simples, Rousseau (1979, p. 32) definia como uma "multidão reunida num corpo". Essa multidão constituiria sua identidade coletiva em sua relação com o Estado e seus governantes:

A pessoa pública, formada assim pela uniáo de todas as outras, tomava outrora o nome de cidade, e toma hoje o de república ou corpo politico, o qual é chamado por seus membros: Estado, quando é passivo; soberano, quando é ativo; autoridade, quando comparado a seus semelhantes. No que concerne aos associados, adquirem coletivamente o nome de povo, e se chamam particularmente cidadãos, na qualidade de participantes na autoridade soberana, e vassalos, quando sujeitos às leis do Estado (ROUSSEAU, 1979, p. 31).

Para Rousseau, o povo seria o corpo de cidadão, que no contexto do Antigo Regime seria constituído, entre outras classes, por burgueses, pequeno-burgueses, camponeses e um operariado ainda em formação. Essa ideia de povo expressa por Rousseau coloca em evidência principalmente a burguesia, que protagonizaria o processo revolucionário francês no final do século XVIII, não sendo possível identificar claramente nesse momento um operariado constituído como classe e sujeito político autônomo. ${ }^{3}$ Em função dessa estrutura social ainda incipiente, não foi possível à formulação teórica de Rousseau se apoiar "no ponto de vista da classe trabalhadora moderna, do proletariado; ele adota o ângulo de visão do pequeno camponês e do artesão, que tinham na época suas condiçôes de vida rapidamente destroçadas pelo avanço do capitalismo" (COUTINHO, 2011, p. 27). Como consequência dessa perspectiva ligada à burguesia em ascensão, "as bases econômicas da sociedade democrática que defende não se fundam na socialização da propriedade, mas sim em sua distribuição igualitária" (COUTINHO, 2011, p. 27).

Uma possibilidade metodológica para estudar o pensamento de Rousseau passa pela análise articulada de $O$ contrato social (1762) e de Discurso sobre a origem e os fundamentos da desigualdade entre os homens (1755). O Contrato seria uma forma de analisar a configuração da sociedade em seu estado civil, o funcionamento das leis, a caracterização dos governos, entre outros aspectos. O Discurso, por outro lado, trataria do período anterior à institucionalizaçáo das relaçóes entre os homens, discutindo uma possível caracterização do surgimento da desigualdade e apontando para a origem da propriedade, portanto, pretende "investigar como se deu a passagem da humanidade

3 Embora o desenvolvimento econômico da França "igualasse (e, em diversos aspectos, superasse) ao desenvolvimento econômico da Revoluçáo Industrial na Inglaterra, deve-se levar em conta, como o próprio Rousseau foi capaz de observar, que as minorias beneficiadas com esse processo estavam compostas apenas pela burguesia e por certas fraçóes de uma aristocracia com mentalidade claramente capitalista" (KERSFFELD, 2006, p. 395). 
do domínio da natureza para o domínio da sociedade” (LIMA, 2008, p. 99). Coutinho (2011, p. 16) afirma que no Contrato apresenta-se a proposta "de formação social e política alternativa àquela que aparece no Discurso".

No Discurso, Rousseau afirma que existem duas espécies de desigualdade, "uma, que chamo natural ou física, porque foi estabelecida pela Natureza, e que consiste na diferença das idades, da saúde, das forças corporais e das qualidades do espírito ou da alma". Quanto à outra, "se pode chamar de desigualdade moral ou política”, pois "depende de uma espécie de convenção e foi estabelecida, ou ao menos autorizada, pelo consentimento dos homens”. Conforme Rousseau, essas espécies de desigualdade consistem "nos diferentes privilégios desfrutados por alguns em prejuízo dos demais, como de serem mais ricos, mais respeitados, mais poderosos que estes, ou mesmo mais obedecidos" (ROUSSEAU, 1979, p. 143). Nessa lógica, portanto, haveria um tipo de desigualdade natural, que se daria por aspectos relacionados principalmente às questóes físicas e mentais, e outra, que se explicaria como construção dos homens vivendo em sociedade.

Para mostrar essas formas de desigualdades, Rousseau utiliza a primeira parte do livro para descrever como viviam os selvagens. Segundo Rousseau, "o corpo do homem selvagem, sendo o único instrumento por ele conhecido, ele o emprega de diversas maneiras, o que, à falta de exercício, os nossos são incapazes de fazer". Para Rousseau, "é nossa indústria que nos tira a força e a agilidade que a necessidade obriga a adquirir" (ROUSSEAU, 1979, p. 147). Esse homem selvagem, vivendo "disperso em meio aos animais, e se achando em boa hora no caso de se medir com eles, tem ocasião de estabelecer frequentes comparaçôes", sendo que, ao perceber "que o sobrepuja em destreza, enquanto que eles o sobrepujam em força, o homem aprende a não mais receá-los" (ROUSSEAU, 1979, p. 148). Por outro lado, Rousseau destaca as enfermidades naturais “inimigos mais terríveis" e "contra os quais não possui o homem os mesmos meios de defesa", apontando nesse caso "a infância, a velhice e as doenças de toda espécie, tristes sinais de nossa fraqueza” (ROUSSEAU, 1979, p. 149).

Esse tema serve para que Rousseau aponte alguns dos males que percebe no estado civil, como a extrema desigualdade na maneira de viver, o excesso de ociosidade por parte de uns, o excesso de trabalho de outros, a facilidade de irritar e de satisfazer nossos apetites e nossa sensualidade, os alimentos demasiadamente requintados, que nos nutrem de sucos abrasantes e nos sobrecarregam de indigestôes, a má alimentação dos pobres, que mesmo assim frequentemente lhes falta e os leva, quando possível, a sobrecarregar avidamente o estômago, as vigílias, os excessos de toda espécie, os imoderados transportes de todas as paixôes, as fadigas e o esgotamento de espírito, os desgostos, as penas inumeráveis experimentadas em todos os estados, e de que as almas estão perpetuamente corroídas: eis, pois, as funestas garantias de que a maioria dos males é fruto de nossa própria obra, e de que seriam quase todos evitados se conservássemos a maneira simples, uniforme e solitária de viver, que nos foi prescrita pela Natureza (ROUSSEAU, 1979, p. 150).

Nesses itens apontados por Rousseau destaca-se uma questão da própria mudança física do ser humano, depois de deixar o estado natural. Não fala explicitamente em uma degeneração, mas Rousseau aponta que a utilização de ferramentas fez o homem perder agilidade e que o estado civil traz maiores males à própria saúde humana. ${ }^{4}$ Nesse caso, não qualquer aspecto da sociedade civil,

4 Para uma discussão acerca da contribuição do trabalho e do uso de ferramentas no processo de evolução, Cf. Silva (2007; 2010). 
mas um elemento ligado à desigualdade, ou mesmo à propriedade, na medida em que tanto o fato de algumas pessoas pouco trabalharem e comerem muito, enquanto outras trabalham demais e comem pouco, são fatores de cansaço físico e de esgotamento mental. $O$ trabalho é ressaltado como fator positivo, enquanto o ócio é entendido como algo que nega a própria natureza humana. Rousseau (1979, p. 153), procurando diferenciar os homens dos animais, aponta que a

Natureza comanda todo animal e este obedece. O homem experimenta a mesma impressão, mas se reconhece livre para aquiescer ou resistir; e é, especialmente, na consciência desta liberdade que se demonstra a espiritualidade de sua alma.

Essa possibilidade de projetar sua própria existência faz do homem, enquanto ser consciente, um ser que, por exemplo, elabora uma linguagem. Conforme Rousseau, "a primeira linguagem do homem, a mais universal, a mais enérgica, e a única de que ele teve necessidade antes de ser preciso persuadir homens reunidos em sociedade, é o grito da Natureza" (ROUSSEAU, 1979, p. 160). Em outro momento, "quando as ideias começaram a estender-se e a multiplicar-se, e foi estabelecida entre eles uma comunicaçáo mais estreita", os homens procuraram "maior número de sinais e uma linguagem mais extensa", multiplicando "as inflexôes da voz", a isso ajuntando "os gestos, que, de natural, são mais expressivos e cujo sentido depende menos de uma determinação anterior" (ROUSSEAU, 1979, p. 160).

Rousseau ressalta também que, no estado natural, "não tendo entre si nenhuma espécie de relação moral nem de deveres conhecidos", os homens "não poderiam ser bons nem maus, e não teriam vícios nem virtudes" (ROUSSEAU, 1979, p. 164). Esse é um passado em que não haveria julgamentos morais ou mesmo crimes como aqueles cometidos no estado civil, marcado pela preponderância de interesses particulares. Nesse sentido, procurando tanto fechar a descrição do estado natural como iniciar a discussão a respeito da desigualdade propriamente dita, aponta que

se torna impossível escravizar uma criatura humana, sem a colocar anteriormente em situação de não poder passar sem a que a escraviza, situação esta que, não existindo no estado natural, deixa aí os homens livres do jugo, e torna vã a lei do mais forte (ROUSSEAU, 1979, p. 174).

Em outros termos, Rousseau está chamando a atenção para o fato de que o domínio dos seres humanos por outros seres humanos estaria relacionado ao fato de alguns homens serem privados da propriedade, que antes era comum. Nesse sentido, aponta no início da segunda parte do Discurso:

$\mathrm{O}$ primeiro que, cercando um terreno, se lembrou de dizer: Isto me pertence, e encontrou criaturas suficientemente simples para o acreditar, foi o verdadeiro fundador da sociedade civil (...) é por demais evidente que, àquela altura, as coisas já tinham chegado ao ponto de não poderem mais durar como duravam: porque essa ideia de propriedade, dependendo de um sem número de ideias anteriores, que não puderam nascer senão sucessivamente, não se formou de inopino no ser humano. Foi preciso conseguir muitos progressos, adquirir muita indústria e muitas luzes, transmiti-los e aumentá-los de idade em idade, antes de se chegar ao derradeiro termos do estado natural (ROUSSEAU, 1979, p. 175).

Essa passagem aponta para duas questóes importantes, desenvolvidas e discutidas ao longo do texto por Rousseau. Primeiro, o surgimento da propriedade aparece como marco para o início do estado civil, ou seja, seria a propriedade o que pôs fim aos elementos considerados positivos do estado natural. Por outro lado, Rousseau apresenta certa simpatia pela sociedade industrial, 
marcada pelos "progressos", que havia posto fim ao estado natural..$^{5}$ Embora enxergasse no estado civil aspectos positivos, não deixaria também de ver no estado civil elementos que teriam aspectos que o agradavam. Contudo, aponta Rousseau (1979, p. 182), "a sociedade começada e as relaçóes já estabelecidas entre os homens exigiam deles qualidades diferentes das que eles possuíam de sua constituição primitiva”.

Nesse sentido, foram inclusive estabelecidas novas formas de lidar com a natureza e transformá-la, organizada de forma particular, o que posteriormente seria chamado de "divisão do trabalho". Segundo Rousseau (1979, p. 185-6),

o mais forte executava maior trabalho; o mais astuto, tirava melhor partido do seu; o lavrador tinha maior necessidade de ferro, ou o ferreiro mais necessidade de trigo; e, trabalhando igualmente, um ganhava demasiado, ao passo que o outro mal tinha com o que viver.

Essa é uma explicação da desigualdade social, ainda que realizada em termos bastante rudimentares. Para Rousseau (1979, p. 186), "a desigualdade natural se desdobra insensivelmente com a de circunstância”, na medida em que

as diferenças existentes entre os homens, desenvolvidas pelas eventuais, se tornam mais profundas, mais permanentes em seus efeitos, e começam a influir na mesma proporção sobre o destino dos particulares.

Essa análise da organização social seria posteriormente apresentada em outros termos por Marx e Engels, buscando mostrar a relação entre a acumulação de riqueza e a exploração do trabalho assalariado. Segundo os pensadores alemães,

a condiçẫo essencial para a existência e supremacia da classe burguesa é a acumulação da riqueza nas mãos de particulares, a formação e o crescimento do capital; a condição de existência do capital é o trabalho assalariado (MARX; ENGELS, 2005, p. 51).

O ponto central dessa desigualdade passa pela propriedade privada, que, conforme mencionado antes, está na passagem do estado natural para o estado civil. Rousseau avança em sua caracterização, apontando que "quando as propriedades aumentaram em número e se estenderam a ponto de cobrir todo o solo e todas se tocarem, umas não se puderam ampliar senão às custas de outras" (ROUSSEAU, 1979, p. 187). Por outro lado,

os excedentes, aos quais a fraqueza ou a indolência tinham impedido de adquirir a sua [propriedade], todos pobres sem nada terem perdido (...) foram forçados a receber ou a arrebatar sua subsistência da mão dos ricos (ROUSSEAU, 1979, p. 187).

Como consequência do processo descrito,

os mais poderosos ou os mais miseráveis fizeram de suas forças ou de suas necessidades uma espécie de direito ao bem alheio, equivalente, segundo eles, ao

\footnotetext{
$5 \quad$ Segundo Kersffeld (2006, p. 397), "as ideias sociais consagradas definitivamente pelo Discurso de Rousseau foram formuladas em concordância com os aportes intelectuais desenvolvidos pelos chamados representantes do 'socialismo ilustrado' (o abade Meslier Morelly e Gabriel Bonnot de Mably), os quais, no transcurso do século XVIII, também efetuaram uma decisiva crítica dirigida, de modo geral, às formas adquiridas pelo capitalismo agrário em auge naquela época na França, e, em particular, à centralidade econômica assumida pela propriedade privada”.
} 
direito de propriedade; e, rompida a igualdade, seguiu-se-lhe a mais espantosa desordem. Foi assim que as usurpaçóes dos ricos, as rapinas dos pobres, as paixóes desenfreadas de todos, abafando a piedade natural e a voz ainda frágil da justiça, tornaram os homens avaros, ambiciosos e perversos (ROUSSEAU, 1979, p. 1878).

Embora sem empregar os termos utilizados no século XIX, Rousseau não está fazendo nada mais do que apresentar uma formulação teórica semelhante ao conceito de luta de classes, que, em sua concepção, passa pela "guerra" entre ricos e pobres. Essa compreensão evidentemente contrasta com a filosofia marxista, para quem "opressores e oprimidos, em constante oposição, têm vivido numa guerra ininterrupta, ora franca, ora disfarçada", que "terminou sempre ou por uma transformação revolucionária da sociedade inteira, ou pela destruição das duas classes em conflito” (MARX \& ENGELS, 2005, p. 40). Mesmo com o processo revolucionário, do qual Rousseau presenciou uma parte, a "sociedade burguesa moderna, que brotou das ruínas da sociedade feudal, não aboliu os antagonismos de classe. Não fez mais do que estabelecer novas classes, novas condições de opressão, novas formas de luta em lugar das que existiam no passado" (MARX \& ENGELS, 2005, p. 40).

Rousseau aponta que, quando foram definidas as propriedades e alguns ficaram com terras e outros não, os ricos elaboram um frágil sistema que garantisse sua legalidade. Esse conjunto de leis náo impede, mas sufoca a "guerra" que se instala pelo direito de propriedade ou, no limite, pelo direito de possuir alguma propriedade. Segundo Rousseau, os ricos sentiam cedo

como lhes era desvantajosa uma guerra perpétua cujas despesas corriam todas por sua conta e na qual o risco da vida era comum, bem como o dos bens particulares" (ROUSSEAU, 1979, p. 188).

No final da obra, Rousseau afirma, concluindo sua exposição,

que a desigualdade, sendo quase nula no estado natural, tira sua força e acréscimo do desenvolvimento de nossas faculdades e dos progressos do espírito humano, e se torna enfim estável e legítima pelo estabelecimento da propriedade e das leis (ROUSSEAU, 1979, p. 206).

Esta afirmação pode servir como ponto de contato entre o Discurso e o Contrato social, onde é possível depreender pelo menos duas discussôes fundamentais a partir da análise conjunta de ambas as obras.

Primeiro, partindo da desigualdade como um fator dado e inclusive discutido, pois teria sido trabalhado em outro texto, Rousseau chama a atenção para uma espécie de esgotamento do estado natural, afirmando textualmente:

Eu imagino os homens chegando ao ponto em que os obstáculos, prejudiciais à sua conservação no estado natural, os arrastam, por sua resistência, sobre as forças que podem ser empregadas por cada indivíduo a fim de se manter em tal estado (ROUSSEAU, 1979, p. 29-30).

Segundo Rousseau, esse estado natural não teria mais como subsistir, afinal a humanidade pereceria se ele não mudasse. Para Rousseau,

depois do estado de natural e antes do contrato, ocorre um longo processo histórico de socialização, através do qual o desenvolvimento das forças produtivas gera várias formaçóes sociais, preparando assim as condiçóes de possibilidade para dois diferentes tipos alternativos de contrato, um que perpetue a sociedade 
injusta, outro que gera uma sociedade livre e igualitária" (COUTINHO, 2011, p. 20).

Essa nova forma de organização da sociedade do estado civil, com base na propriedade, precisa encontrar uma forma de associaçáo que defenda e proteja as pessoas, os bens, enfim, a sociedade, devendo cada um obedecer a essas normas que se estabeleçam. O contrato social, para Rousseau, seria a solução. Com isso se estabeleceria um conjunto de leis que pudessem regular o funcionamento desse contrato, expressando uma soberania dos cidadáos e regulando o funcionamento da própria sociedade. Segundo Rousseau, "o que o homem perde pelo contrato social é a liberdade natural e um direito ilimitado a tudo que o tenta e pode alcançar; o que ganha é a liberdade civil e a propriedade de tudo o que possui" (ROUSSEAU, 1979, p. 34). Essa interpretação dialoga com aquela exposta pelos fundadores do marxismo, quando afirmam:

Esboçando em linhas gerais as fases do desenvolvimento proletário, descrevemos a história da guerra civil mais ou menos oculta na sociedade existente, até a hora em que essa guerra explode numa revoluçáo aberta e o proletariado estabelece sua dominação pela derrubada violenta da burguesia (MARX, Karl; ENGELS, 2005, p. 50).

Um segundo aspecto que pode ser destacado passa pela criação de leis que regem a sociedade. Segundo Rousseau (1979, p. 47), é preciso "que haja convençôes e leis para unir os direitos aos deveres e encaminhar a justiça a seu objetivo”. Essas leis são as condiçóes a partir das quais se dão a associação civil. Contudo, embora Rousseau (1979, p. 49) afirma que "o povo, submetido às leis, deve ser o autor das mesmas", demonstra desconfiança em relação à "turba cega, que em não sabe o que quer, porque raramente conhece o que lhe convém".

Pode-se depreender disso que Rousseau, ao procurar a origem e os fundamentos da desigualdade, percebe que ela está justamente no surgimento da propriedade, ou seja, da passagem de um estado selvagem para um estado civil. Surge disso a necessidade de constituir um contrato e formular leis que garantam direitos, seja o de propriedade, seja o de liberdade. Nesse processo é constituído o Estado, que "tem uma origem humana, tem uma história que é feita pelo homem. $\mathrm{O}$ Estado coloca o homem fora da história natural. E, se é o homem que, pelo seu desenvolvimento, organizou o Estado, logo é um contrato social que o fundamenta” (LIMA, 2008, p. 103). Uma crítica radical do Estado, relacionando sua origem e fundamentos à propriedade privada e à exploraçáo do trabalho, seria formulada apenas no século seguinte, por Marx e Engels.

\section{CONSIDERAÇÕES FINAIS}

No Discurso, Rousseau está procurando os fundamentos da desigualdade existente entre as pessoas. No Contrato busca entender de que forma opera o poder soberano, embora mostre, por um lado, uma simpatia saudosista em relação ao passado humano e, por outro, uma visão positiva da soberania do povo. Mas essa soberania exigiria igualdade e liberdade, o que Rousseau não enxergava na sociedade em que viveu. Por outro lado, sua ideia de "povo" se remete mais a uma burguesia em consolidação na estrutura do Estado e a camadas "ilustradas" da aristocracia, e menos ao proletário, que apenas começava a dar seus primeiros passos em sua organização política. Rousseau, portanto, apresenta uma ideia de democracia sustentada nos interesses da burguesia, superando o modelo centrado nas classes que governavam o Antigo Regime, problematizando a disparidade na 
distribuição de riquezas, mas sem apontar para a necessidade de superação da exploração de uma classe por outra.

\section{REFERÊNCIAS}

COUTINHO, Carlo Nelson. De Rousseau a Gramsci: ensaios de teoria política. São Paulo: Boitempo, 2011.

KERSFFELD, Daniel. Rousseau e a busca mítica da essencialidade. BORON, Atílio (Org.). Filosofia política moderna: de Hobbes a Marx. São Paulo: Departamento de Ciência Política - USP, 2006.

LIMA, Carlos. Genealogia dialética da utopia. Rio de Janeiro: Contraponto, 2008.

MARX, Karl; ENGELS, Friedrich. Manifesto comunista. São Paulo: Boitempo, 2005.

ROUSSEAU, Jean-Jacques. O contrato social e outros escritos. São Paulo: Cultrix, 1979.

SILVA, Michel Goulart da. O macaco e o trabalho. Revista Urutágua, № 14, 2007.

SILVA, Michel Goulart da (Org.). Marxismo e natureza: ecologia, história e política. Pará de Minas: Editora VirtualBooks, 2010. 